\title{
Asymmetric cell division and axis formation in the embryo*
}

Pierre Gönczy ${ }^{\S}$, Swiss Institute for Experimental Cancer Research, (ISREC), $\mathrm{CH}-1066$ Epalinges/Lausanne, Switzerland

Lesilee S. Rose ${ }^{\S}$, Section of Molecular and Cellular Biology, University of California, Davis, CA USA 95616

\section{Table of Contents}

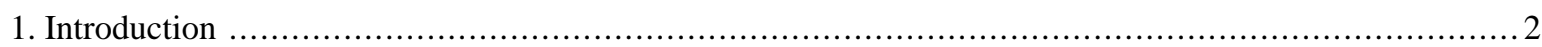

2. The one-cell stage embryo: establishment of the anterior-posterior axis ................................ 4

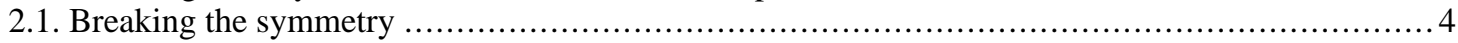

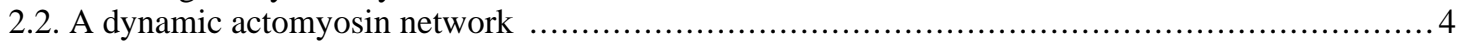

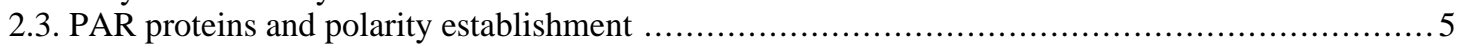

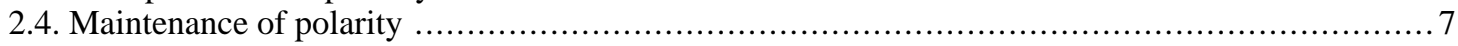

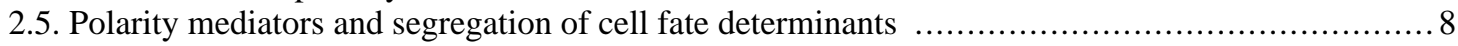

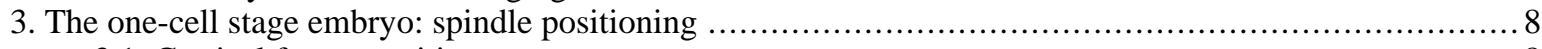

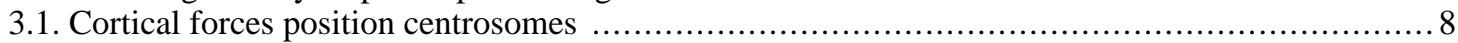

3.2. A $\mathrm{G}$ protein pathway transduces polarity cues to a force generation machinery $\ldots \ldots \ldots \ldots \ldots \ldots \ldots \ldots$

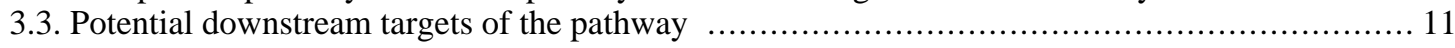

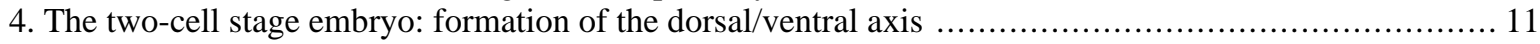

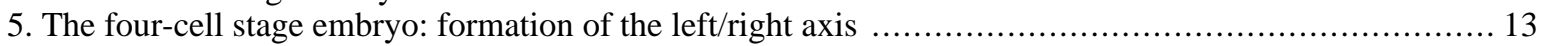

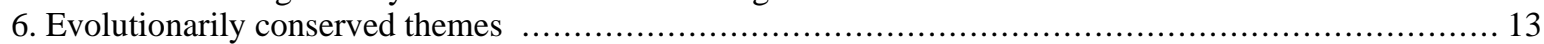

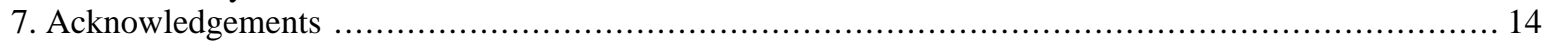

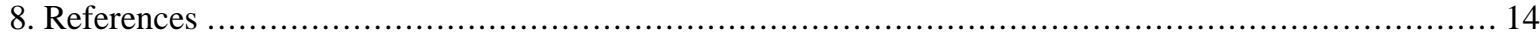

\begin{abstract}
Asymmetric cell divisions play an important role in generating diversity during metazoan development. In the early $C$. elegans embryo, a series of asymmetric divisions are crucial for establishing the three principal axes of the body plan (AP, DV, LR) and for segregating determinants that specify cell fates. In this review, we focus on events in the one-cell embryo that result in the establishment of the AP axis and the first
\end{abstract}

\footnotetext{
*Edited by Geraldine Seydoux and James R. Priess. Last revised October 13, 2005. Published October 15, 2005. This chapter should be cited as: Gönczy, P. and Rose, L.S. Asymmetric cell division and axis formation in the embryo (October 15, 2005), WormBook, ed. The C. elegans Research Community, WormBook, doi/10.1895/wormbook.1.30.1, http://www.wormbook.org.

Copyright: (C) 2005 Pierre Gönczy and Lesilee S. Rose. This is an open-access article distributed under the terms of the Creative Commons Attribution License, which permits unrestricted use, distribution, and reproduction in any medium, provided the original author and source are credited.

${ }_{\text {§ }}$ To whom correspondence should be addressed. E-mail: Pierre.Gonczy@isrec.unil.ch or 1srose@ucdavis.edu
} 
asymmetric division. We first describe how the sperm-derived centrosome initiates movements of the cortical actomyosin network that result in the polarized distribution of PAR proteins. We then briefly discuss how components acting downstream of the PAR proteins mediate unequal segregation of cell fate determinants to the anterior blastomere $\mathrm{AB}$ and the posterior blastomere $P_{1}$. We also review how a heterotrimeric $G$ protein pathway generates cortically based pulling forces acting on astral microtubules, thus mediating centrosome and spindle positioning in response to AP polarity cues. In addition, we briefly highlight events involved in establishing the DV and LR axes. The DV axis is established at the four-cell stage, following specific cell-cell interactions that occur between $P$ and EMS, the two daughters of $P$, as well as between $P$ and $A B p$, a daughter of $\mathrm{AB}$. The $\mathrm{LR}$ axis is established shortly thereafter by the division pattern of $\mathrm{ABa}$ and $\mathrm{ABp}$. We conclude by mentioning how findings made in early $C$. elegans embryos are relevant to understanding asymmetric cell division and pattern formation across metazoan evolution.

\section{Introduction}

Asymmetric divisions are crucial for generating diversity during development because they yield daughter cells that differ in fate. In C. elegans embryos, five asymmetric divisions produce six founder cells: AB, MS, E, C, $\mathrm{D}$ and $\mathrm{P}_{4}$ (Figure 1; see also Movie 1 and Movie 2). The first asymmetric division parts the zygote into the larger anterior blastomere $\mathrm{AB}$ and the smaller posterior blastomere $\mathrm{P}$. In turn, $\mathrm{P}$ undergoes an asymmetric division that yields EMS and $\mathrm{P}_{2}$. Further asymmetric division of EMS into MS and E, of $\mathrm{P}$ into $\mathrm{C}$ and $\mathrm{P}_{3}$, and then of $\mathrm{P}_{3}$ into $\mathrm{D}$ and $\mathrm{P}_{4}$, completes the generation of six founder cells whose descendants each produce a specific subset of cell types (Sulston et al., 1983).

During these early cleavage divisions, the three principal axes of the body plan are established. First, the anterior-posterior (AP) axis is set up in the one-cell stage, with the sperm-derived centrosome breaking the symmetry of the oocyte and initiating a sequence of events relying on maternally-contributed proteins. Second, the dorso-ventral (DV) axis becomes apparent at the transition between the two- and four-cell stage, with EMS defining the ventral side of the embryo. Third, the left-right (LR) axis is detectable at the transition between the four- and six-cell stage, with the location of two granddaughters of $\mathrm{AB}$ (ABal and ABpl) defining the left side of the embryo. Because the position of the mitotic spindle in animal cells determines the relative size and spatial relationship of daughter cells (reviewed in Rappaport, 1971), proper spindle positioning during these early cleavage divisions is crucial for correct segregation of cell fate determinants and cell division patterns.

In this brief review, we discuss the principal mechanisms governing asymmetric division and axis formation during early $C$. elegans embryogenesis. Due to space constraints, we refer the reader to other publications for a more detailed coverage of the underlying data.

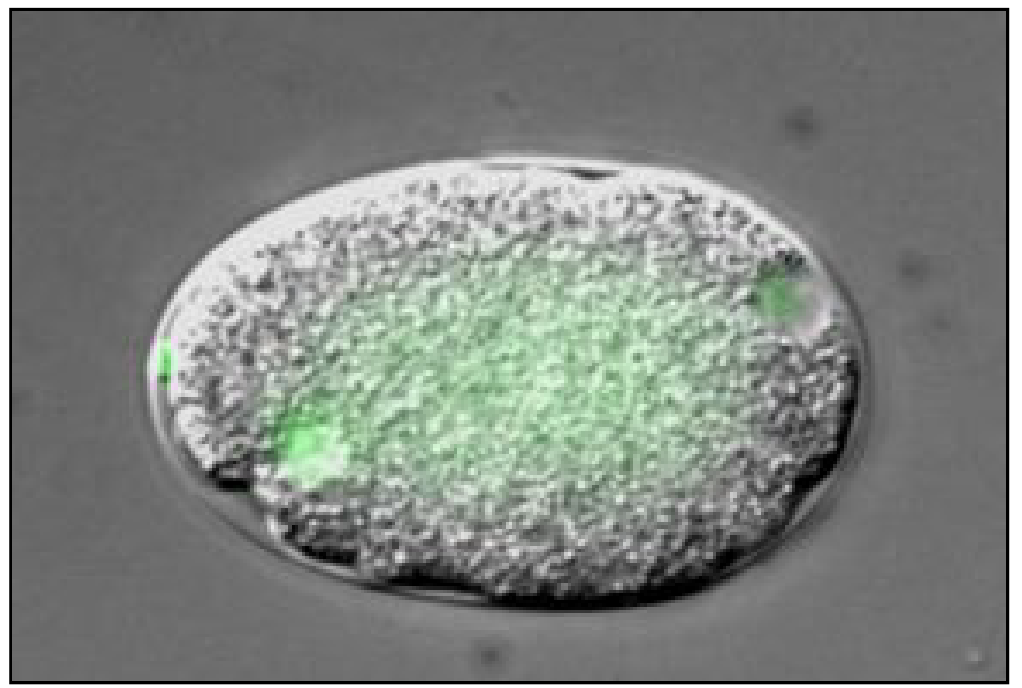

Movie 1. Embryo carrying a GFP-histone2B fusion protein (Strome et al., 2001) imaged using dual time-lapse differential interference contrast (DIC) and fluorescence microscopy from the one-cell stage until the four-cell stage. One image was captured every ten seconds, and the movie is played back at 10 frames per seconds (overall, 100 times faster than actual events). The DIC and GFP signal (pseudocolored in green) are overlaid. The embryo is approximately $50 \mu \mathrm{m}$ long and anterior is to the left. 
A

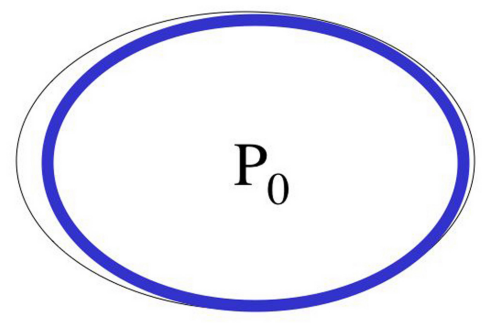

B

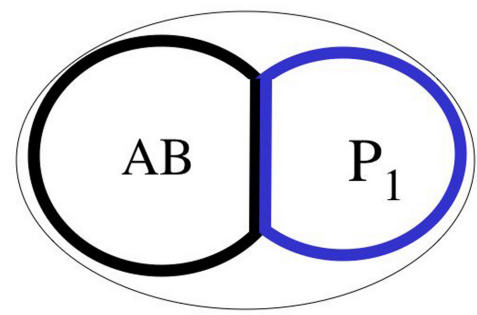

C

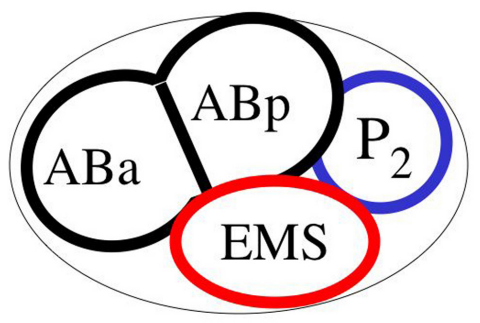

D

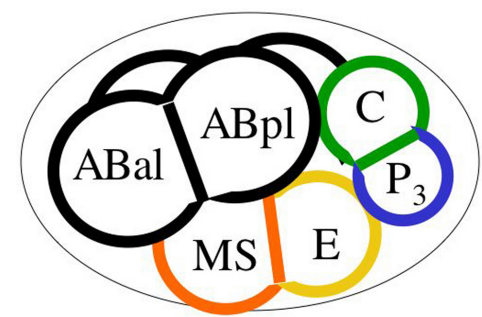

$E$

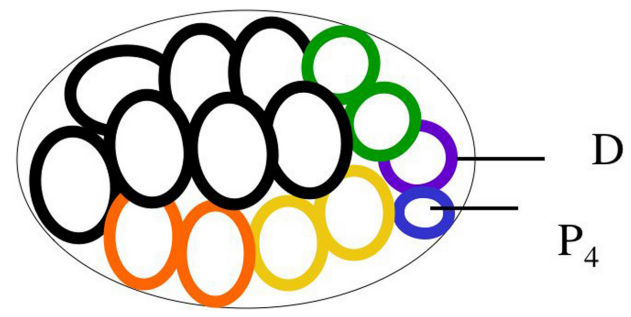

\section{anterior}

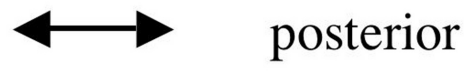

Figure 1. Generation of founder cells in the early embryo. Anterior is to the left, posterior to the right, dorsal is up and ventral down in this and all subsequent figures. The germ-line precursors (P cells) are shown outlined with blue. Each of the founder cells generated by asymmetric division are indicated with a different color. The founder cells each display a characteristic cell cycle rate and lineage: The AB lineage produces hypodermis, neurons, anterior pharynx and other cell types; MS produces the somatic gonad, muscle, the majority of the pharynx, neurons and gland cells; E produces all intestine; $\mathrm{C}$ produces muscle, hypodermis and neurons; $\mathrm{D}$ produces muscle; $\mathrm{P}_{4}$ is the germ-line precursor. The 16-cell embryo shown in (E) is simplified and does not show the daughters of the $4^{\text {th }} \mathrm{AB}$ cell division, which occurs at approximately the same time as the $\mathrm{P}_{3}$ division. 


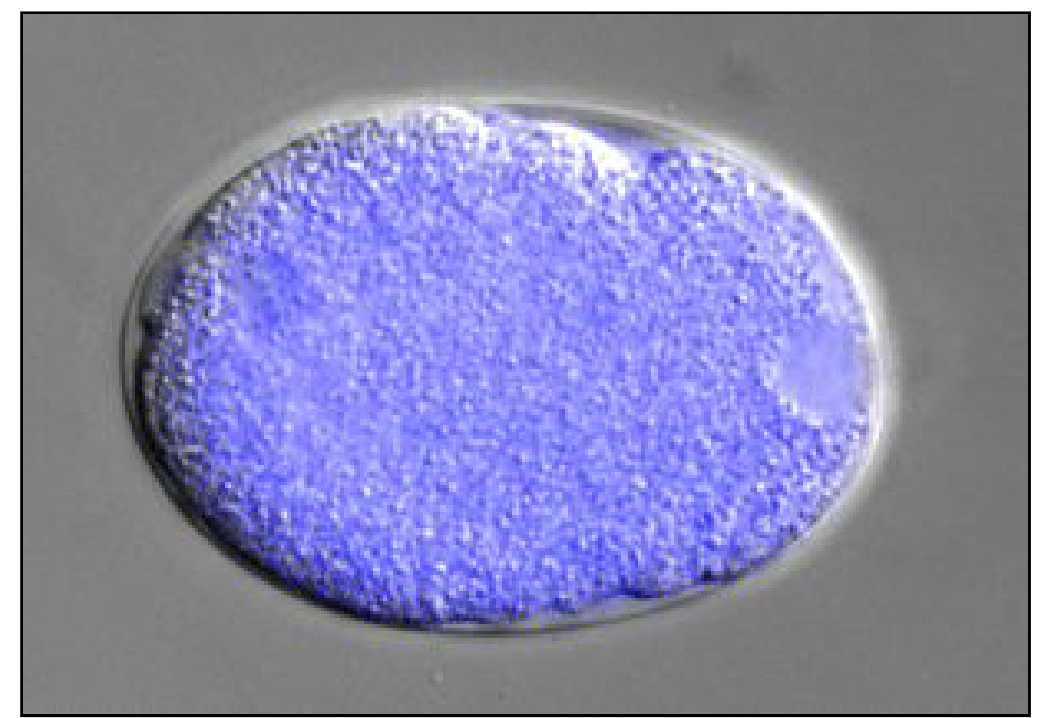

Movie 2. Embryo carrying a GFP-PIE-1 fusion protein (Reese et al., 2000) imaged using dual time-lapse DIC and fluorescence microscopy from the one-cell stage until the four-cell stage. One image was captured every ten seconds, and the movie is played back at 10 frames per seconds (overall, 100 times faster than actual events). The DIC and GFP signal (pseudocolored in blue) are overlaid. The embryo is approximately $50 \mu \mathrm{m}$ long and anterior is to the left.

\section{The one-cell stage embryo: establishment of the anterior-posterior axis}

\subsection{Breaking the symmetry}

In C. elegans, formation of the AP axis is initiated after fertilization, which takes place when a mature oocyte traverses the spermatheca and encounters a sperm cell. The newly fertilized zygote then moves into the uterus where the remainder of early embryogenesis takes place. In wild-type animals, sperm usually enters the egg opposite from the side of the oocyte nucleus. In addition to DNA, the sperm donates a pair of centrioles that assembles pericentriolar material (PCM) to form a centrosome that nucleates microtubules. Importantly, experiments in which the sperm entry site was altered established that a sperm component confers posterior character to the zygote (Goldstein and Hird, 1996).

What is the nature of this symmetry-breaking cue? The cue does not appear to be the sperm entry site or paternally-contributed DNA (Goldstein and Hird, 1996; Sadler and Shakes, 2000). Early results indicated that the sperm-associated microtubule aster might correspond to the cue. Mutations in $s p d-2$, spd-5 or air-1 that prevent PCM assembly and hence formation of astral microtubules also prevent polarity establishment (Hamill et al., 2002; O'Connell et al., 2000; Wallenfang and Seydoux, 2000). However, these results could not distinguish whether the cue depends on the PCM or on the microtubules it nucleates. The finding that embryos blocked in meiosis exhibit a polarity reversal correlating with the position of ectopic microtubule arrays suggested a prominent role for microtubules (Wallenfang and Seydoux, 2000). However, more recent evidence indicates that the centrosome per se is key. Laser-mediated ablation of the centrosome prevents polarity establishment (Cowan and Hyman, 2004), whereas elimination of all detectable microtubules following RNAi-mediated inactivation of tubulin genes does not (Cowan and Hyman, 2004; Sonneville and Gönczy, 2004). Therefore, unless extremely attenuated microtubules provide the cue, these experiments demonstrate that the centrosome or a specific protein contained within it breaks the symmetry of the zygote.

\subsection{A dynamic actomyosin network}

Physical association of the centrosome with the posterior cortex appears crucial for initiating the sequence of events that result in polarization of the embryo along the AP axis. Consistent with this view, proper AP polarity is not established in embryos in which this close association does not occur due to impairment of fatty acid synthesis or APC (Anaphase Promoting Complex) function (Rappleye et al., 2003; Rappleye et al., 2002). In wild-type animals, the entire cortex undergoes surface contractions after fertilization (Figure 2A), and these movements cease in a local manner after the centrosome becomes juxtaposed to the presumptive posterior cortex (Cheeks et al., 2004; Cowan and Hyman, 2004; Cuenca et al., 2003; Munro et al., 2004). The smoother cortical area expands gradually 
towards the anterior until approximately 50\% egg-length, concomitant with a flow of cortical material and neighboring yolk granules (Figure 2B; Hird and White, 1993). This anterior-directed cortical movement is compensated by posterior-directed flow of cytoplasmic material (Hird and White, 1993).

Whereas it has been long recognized that actin is required for AP polarity (Strome and Wood, 1983), recent observations further clarified the relationship between the centrosome and the actin cytoskeleton. Imaging of the non-muscle myosin II heavy chain NMY-2 fused to GFP revealed the presence of a dynamic meshwork of filaments connecting denser foci (Munro et al., 2004; see also Movie 3). Whereas this cortical network is initially distributed in a uniform manner (Figure 2A), GFP-NMY-2 foci cease to form in the posterior following association of the sperm aster with the cortex. By contrast, existing foci move in an anterior-directed manner, indicating a contraction of the entire network (Figure 2B). Furthermore, the distribution of F-actin, as well as that of the E-cadherin HMR-1 and the $\beta$-catenin HMP-2, demonstrates that the behavior observed with GFP-NMY-2 reflects that of the entire cortical actomyosin network (Munro et al., 2004).

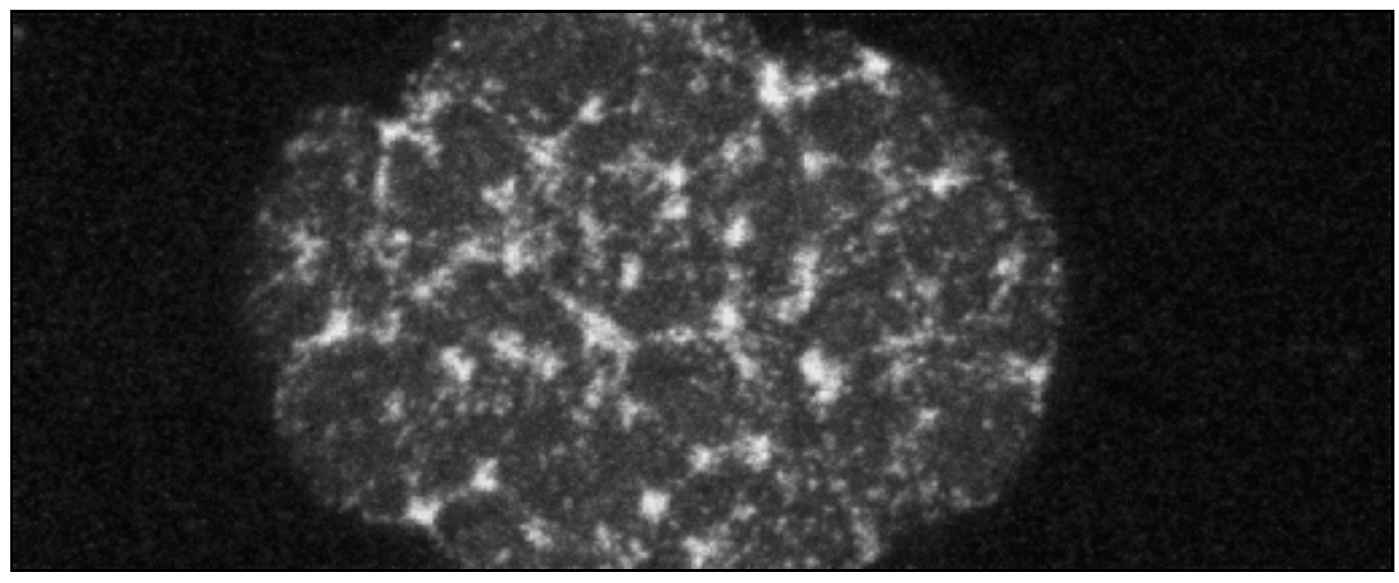

Movie 3. One-cell stage embryo carrying a GFP-NMY-2 fusion protein (Munro et al., 2004) imaged using time-lapse confocal microscopy from late meiosis II until the first cleavage. A projection of confocal slices corresponding to $3.5 \mu \mathrm{m}$ of cell cortex is shown. The movie is displayed $\sim 150$ times faster than actual events. The embryo is approximately $50 \mu \mathrm{m}$ long and anterior is to the left.

\subsection{PAR proteins and polarity establishment}

Contraction of the actomyosin network is crucial for establishing asymmetric distribution of PAR proteins in one-cell stage embryos (Figure 2, Figure 3). The six par genes (for partitioning defective) were identified in screens for maternal-effect mutations that result in defective AP polarity in the one-cell stage, as evidenced by the generation of daughter cells with altered fate, size, spindle orientation and cell cycle progression (Kemphues et al., 1988; reviewed in Kemphues and Strome, 1997; Rose and Kemphues, 1998b). PAR-3 and PAR-6 are PDZ-containing proteins that form a complex with the atypical protein kinase C, PKC-3. The distribution of this complex is restricted to the anterior cortex by the end of prophase. At that time, PAR-2, a Ring-finger protein, and PAR-1, a Ser/Thr kinase, localize in a reciprocal manner to the posterior cortex. PAR-4, another Ser/Thr kinase, and PAR-5, a 14-3-3 protein, are present in a uniform manner throughout the cortex, as well as in the cytoplasm. Systematic examination of PAR protein distributions in fixed embryos lacking the function of one of the other par genes led to the view that par-5, par-2, par-3 and par-6 act upstream of par-1, whereas par-4 may function in a separate pathway (reviewed in Kemphues and Strome, 1997; Rose and Kemphues, 1998b).

More recently, live imaging studies have led to a richer description of these relationships and of the dynamics of PAR protein distribution during AP polarity establishment. Imaging of GFP-PAR-6 indicates that whereas the anterior PAR complex (PAR-3/PAR-6/PKC-3) is present throughout the cortex shortly after fertilization, it recedes from the posterior soon after centrosome juxtaposition with the cortex, to eventually reach approximately $50 \%$ egg-length (Cuenca et al., 2003). Conversely, GFP-PAR-2 becomes enriched on the posterior cortex in the vicinity of the centrosome shortly after onset of cortical smoothing and then extends anteriorly to approximately $50 \%$ egg-length (Cuenca et al., 2003). Cortical flows of GFP-PAR-6 occur concomitantly with movements of GFP-NMY-2 and both are severely diminished when contraction of the actomyosin network is compromised by depletion of the regulatory myosin light chain mlc-4 (Munro et al., 2004). Similarly, anterior expansion of GFP-PAR-2 does not occur in $n m y$-2(RNAi) embryos (Cuenca et al., 2003). Interestingly, fluorescence recovery 
after photobleaching (FRAP) shows that both GFP-PAR-6 and GFP-PAR-2 dynamically associate with the cell cortex during this cortical flow, indicating that they somehow recognize specific features of the receding and advancing cortices, respectively (Cheeks et al., 2004).

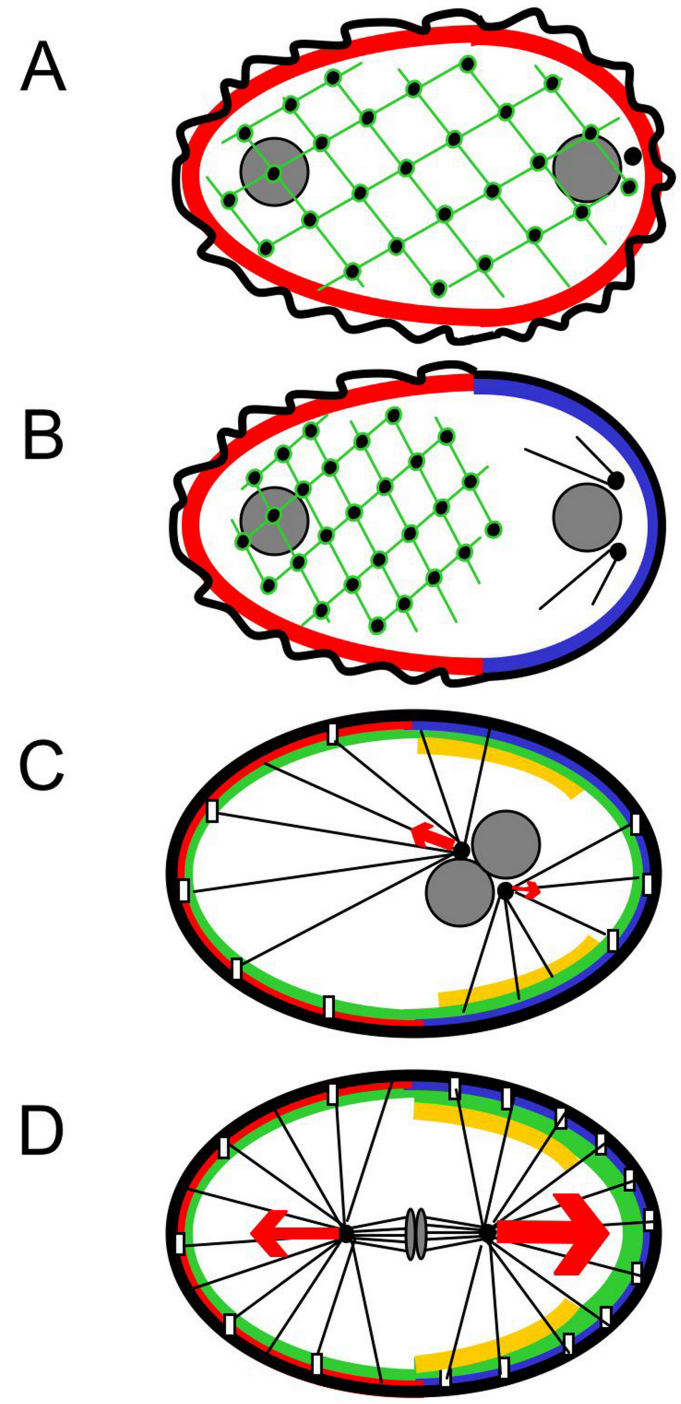

Figure 2. AP polarity and spindle positioning in one-cell stage embryos. Centrosomes: black discs; microtubules: black lines; chromosomes, pronuclei and nuclei: gray ovals and discs; NMY-2: green network and foci; cortical PAR-3/PAR-6/PKC-3: red; cortical PAR-2 and PAR-1: blue; cortical GPR-1/2: green; cortical LET-99: gold. Note that the levels of GPR-1/2 and LET-99 increase during the cell cycle; for simplicity, LET-99 is shown as a band, but lower levels are present throughout the remaining cortex. Cortical force generators are represented with empty rectangles, the net pulling force acting on each spindle pole with red arrows. Four successive time-points are shown. (A) Shortly after fertilization, the whole cortex undergoes surface contractions and the network of cortical NMY-2 spans the entire embryo. Physical interaction between the centrosome and the posterior cortex breaks the symmetry of the oocyte and initiates AP polarity establishment. (B) Surface contractions cease in the presumptive posterior and a smoother cortical area expands anteriorly to approximately 50\% egg-length. Concomitantly, the NMY-2 network contracts while moving towards the anterior. During this time, GFP-PAR-2 expands towards the anterior, whereas GFP-PAR-6 retracts from the posterior, both to approximately 50\% egg-length. Note that centrosomes have duplicated at this stage and that they nucleate numerous astral microtubules. (C) Following pronuclear migration and meeting, the centrosomes and pronuclei move as a unit towards the cell center, while rotating by $90^{\circ}$ such that centrosomes become aligned with the AP axis. (D) During mitosis, unequal net pulling forces act on the two spindle poles, with larger pulling forces acting on the posterior spindle pole.

Whereas contraction of the actomyosin network plays a crucial role in establishing distinct domains of GFP-PAR-6 and GFP-PAR-2, par genes are required to generate robust cortical flows. Although cortical flows are similar to wild-type animals in par-1 mutant embryos, they are essentially abolished in embryos lacking par-3 or par-6 function (Cheeks et al., 2004). Flows are likewise absent in embryos lacking MEX-5/MEX-6 (Cheeks et al., 2004), two partially redundant CCCH finger proteins that also play a role in setting up AP polarity (Cuenca et al., 2003; Schubert et al., 2000). Furthermore, the movement of GFP-NMY-2 foci away from the posterior is greatly attenuated in embryos lacking one of the anterior PAR complex components (Munro et al., 2004). Interestingly, flows are also abolished in par-4 mutant embryos (Cheeks et al., 2004), in which PAR-6, PAR-3 and PAR-2 
distribution are normal initially (Boyd et al., 1996; Etemad-Moghadam et al., 1995; Hung and Kemphues, 1999), indicating an apparent uncoupling between the presence of flows and proper distribution of PAR-3 and PAR-2. However, PAR-6 and PAR-3 do expand towards the posterior by the end of the one-cell stage in par-4 embryos (Hung and Kemphues, 1999). Cortical flows also appear compromised in par-5 mutant embryos (Cheeks et al., 2004); in this case, PAR-3 and PAR-2 can overlap, indicating a unique role for par-5 in maintaining distinct anterior and posterior cortical domains (Morton et al., 2002). In embryos lacking par-2 function, rates of cortical flow and of GFP-NMY-2 movements are normal initially (Cheeks et al., 2004; Munro et al., 2004). Probably as a consequence, retraction of GFP-PAR-6 from the embryo posterior during this establishment phase occurs normally in par-2 mutant embryos (Cuenca et al., 2003).

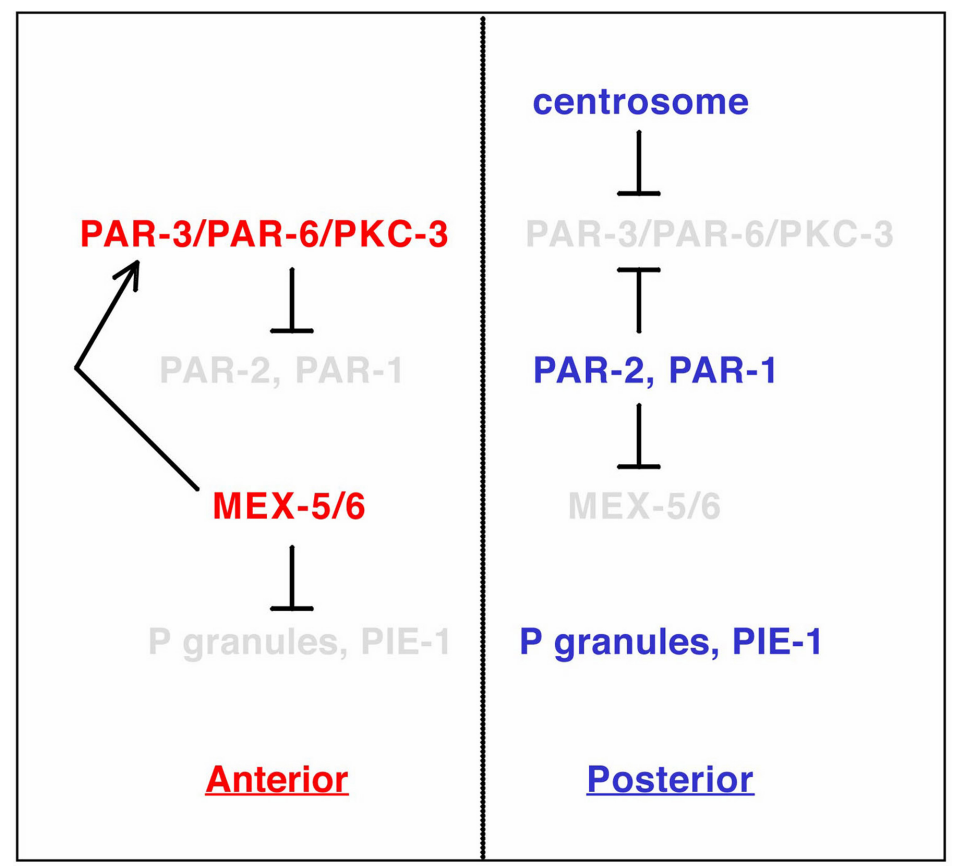

Figure 3. Sequential relationships between AP polarity components in one-cell stage embryos. Contact between the centrosome and the cortex breaks the symmetry of the zygote and results in PAR-3/PAR-6/PKC-3 receding from the posterior in an NMY-2-dependent manner. Meanwhile, PAR-2 enrichment at the posterior occurs concomitant with that of PAR-3/PAR-6/PKC-3 at the anterior. In turn, PAR-1 prevents MEX-5/6 accumulation at the posterior. The presence of MEX-5/6 at the anterior prevents the presence of $\mathrm{P}$ granules and PIE- 1 on that side of the embryo, and also reinforces anterior PAR-3/PAR-6/PKC-3 distribution. As a result of this sequence of interactions, P granules and PIE-1 are segregated to the posterior of one-cell stage embryos.

\subsection{Maintenance of polarity}

The above phase of polarity establishment is followed by a distinct maintenance phase that begins just after meeting of the male and female pronuclei. During this second phase, laser-mediated ablation of the centrosome does not abolish AP polarity - although small alterations in the extent of the GFP-PAR-6 cortical domain are observed (Cowan and Hyman, 2004). Moreover, par-2 is required during this phase to maintain GFP-PAR-6 restricted to the anterior cortex. In par-2 mutant embryos, cortical GFP-PAR-6 abnormally returns towards the posterior to occupy the entire circumference of the embryo (Cuenca et al., 2003). This may be due to the abnormal posterior-directed cortical movements of GFP-NMY-2 that occur concomitantly and which may prevent maintenance of PAR asymmetries (Munro et al., 2004).

Another component important for the maintenance of AP polarity is the small G protein CDC-42 (Gotta et al., 2001; Kay and Hunter, 2001). In $c d c-42(R N A i)$ embryos, polarity appears to be correctly established, because initially PAR-6 localizes to the anterior cortex and PAR-2 to the posterior cortex. However, these asymmetries are not maintained. Although CDC-42 distribution has not been reported, the protein physically interacts with PAR-6 in a yeast two-hybrid assay (Gotta et al., 2001), as is the case in other organisms. Because Cdc42 is a universal regulator of the actin cytoskeleton, an attractive possibility is that $C$. elegans CDC-42 may somehow modulate the actomyosin network during the maintenance phase to prevent posterior flow of NMY-2. 


\subsection{Polarity mediators and segregation of cell fate determinants}

After AP polarity has been established and maintained, several components act downstream of the PAR proteins to mediate unequal segregation of cell fate determinants during early embryogenesis (Figure 3, Figure 4). Whereas such polarity mediators and cell fate determinants will be mentioned briefly here, other chapters in this collection are devoted to a more detailed discussion of their nature and mechanism of action.

Polarity mediators include the CCCH-finger proteins MEX-1 (Guedes and Priess, 1997; Mello et al., 1992), MEX-5/6 (Schubert et al., 2000) and POS-1 (Tabara et al., 1999), as well as the putative RNA binding proteins MEX-3 (Draper et al., 1996) and SPN-4 (Gomes et al., 2001). Inactivation of polarity mediators does not abolish AP polarity, but prevents correct segregation of cell fate determinants. Although clear in principle, the distinction between polarity proteins and polarity mediators can be difficult to make in practice. For instance, MEX-5/6 help restrict PAR-3/PAR-6/PKC-3 to the anterior during polarity establishment (Cuenca et al., 2003), but are also regulated by PAR proteins as loss of PAR-1 prevents MEX-5/6 asymmetric distribution (Cuenca et al., 2003; Schubert et al., 2000). Therefore, MEX-5/6 can be considered both as polarity proteins and as polarity mediators.

Three principal mechanisms ensure unequal segregation of cell fate determinants during early embryogenesis in response to AP polarity: directed transport, localized degradation and translational control (see Specification of the germ line and Translational control of maternal RNAs). The segregation of P granules (Figure 3; Figure 4), large ribonucleoprotein complexes destined to the germ line, provides a good example for protein transport: present uniformly in the cytoplasm at fertilization, $\mathrm{P}$ granules move towards the posterior of the one-cell embryo concomitantly with cytoplasmic flows (Hird et al., 1996; Strome and Wood, 1983). In addition, localized degradation contributes to clearing of $\mathrm{P}$ granules from the anterior. Similarly, localized degradation of the CCCH-finger protein PIE-1 (Mello et al., 1996), a regulator of germ line fate, exemplifies the second type of mechanism. PIE-1 is restricted to germ line precursors (Figure 3; Figure 4) in part because protein remaining in somatic blastomeres is degraded by a CUL-2-based E3 ligase (DeRenzo et al., 2003; Reese et al., 2000). Translational control of PAL-1, a determinant necessary for the fate of posterior blastomeres (Waring and Kenyon, 1990), provides an example of the last principal mechanism. Whereas pal-1 mRNA is present throughout the early embryo, PAL-1 protein becomes detectable only starting at the four cell stage and strictly in posterior blastomeres (Hunter and Kenyon, 1996; Figure 4C). The repression of PAL-1 in the anterior is mediated by the KH domain protein MEX-3, whose activity is restricted to the anterior by PAR-1 (Huang et al., 2002).

\section{The one-cell stage embryo: spindle positioning}

\subsection{Cortical forces position centrosomes}

Following polarity establishment, proper spindle positioning is critical for ensuring that cell fate determinants are correctly segregated to daughter cells during asymmetric division. In one-cell stage embryos, spindle positioning follows from two processes: placement of centrosomes along the AP axis during prophase, and asymmetric spindle movements along the AP axis during mitosis (Figure 2C-D; Albertson, 1984; Nigon et al., 1960). Importantly, both processes are dependent upon the PAR proteins, which thus coordinate segregation of cell fate determinants with spindle positioning (Cheng et al., 1995; Grill et al., 2001; Kemphues et al., 1988; Tsou et al., 2003).

After migration of the female pronucleus towards the male pronucleus and its associated centrosomes at the embryo's posterior, the centrosomes and pronuclei move as a unit towards the embryo's center during prophase (centration). The unit also rotates by $90^{\circ}$ such that the centrosomes become aligned with the AP axis (rotation), typically before nuclear envelope breakdown (Albertson, 1984; Hyman and White, 1987). During metaphase, the entire spindle moves slightly towards the posterior (Labbé et al., 2004; Oegema et al., 2001), whereas the spindle elongates asymmetrically at anaphase (Albertson, 1984; Grill et al., 2001; Nigon et al., 1960); the posterior spindle pole moves farther towards the cortex than the anterior one, thus dictating unequal cleavage. During anaphase, the posterior spindle pole also exhibits vigorous transverse oscillations while the anterior spindle pole remains relatively stationary. In addition, the posterior spindle pole assumes a disc shape during telophase. 
A

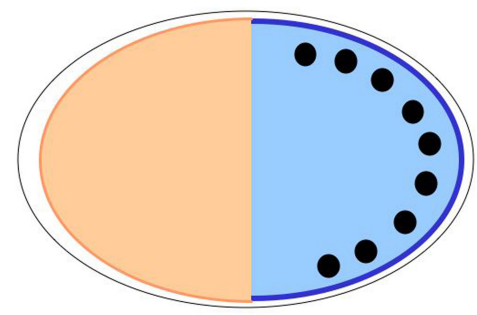

B

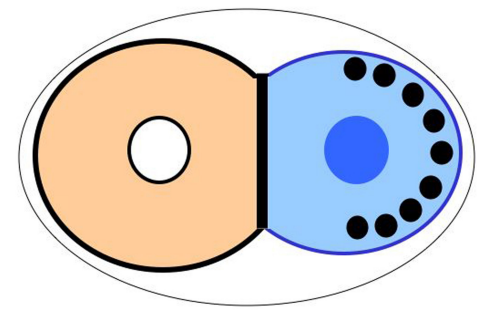

C

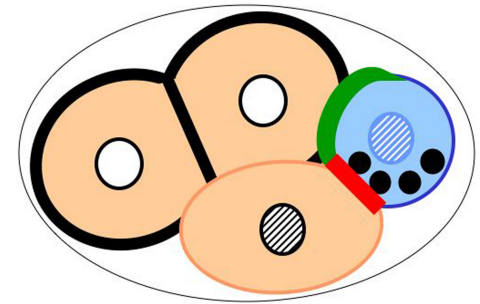

D

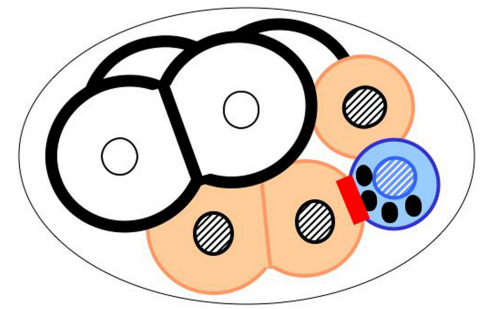

Figure 4. Asymmetric localization of polarity mediators and cell fate determinants in the early embryo. P granules: black discs; cytoplasmic POS-1, MEX-1, and cytoplasmic and nuclear PIE-1: blue; nuclear PAL-1: hatched; MEX-5 and MEX-3: peach; plasma membrane localized GLP-1: black; membrane localized APX-1: green; membrane localized MES-1: red. Although shown discreetly localized for simplicity, the cytoplasmic proteins are present at low levels in the opposite domain before division, and in the sister cell after division. In addition, MEX-5, MEX-3, MEX-1, POS-1 and PIE-1 are also present on P granules. (A) MEX-5, MEX -3, MEX-1, PIE-1, POS-1 and P granules are uniformly present in the cytoplasm just after fertilization, but become asymmetrically localized during the one-cell stage. (B) The anterior and posterior determinants are differentially segregated to $\mathrm{AB}$ and $\mathrm{P}$ as a result of the first asymmetric division. GLP-1 protein first appears in AB at the two-cell stage, and PIE-1 protein enters the nucleus in addition to being cytoplasmic. As the cell cycle proceeds (not shown), posterior determinants become restricted to the posterior half of $\mathrm{P}_{1}$, while MEX-5 appears in the anterior half of $\mathrm{P}$. (C) In the four-cell embryo, GLP-1 is expressed on membranes of both AB cells, but only $\mathrm{ABp}$ is in contact with the $\mathrm{P}$ cell expressing APX-1. MES-1 is enriched at the cell contact between $\mathrm{P}_{2}$ and EMS; MES-1/SRC-1 signaling in conjunction with Wnt signaling polarizes the EMS cell, such that it will divide asymmetrically. As the cell cycle proceeds, posterior determinants within $\mathrm{P}_{2}$ become asymmetrically localized as in previous $\mathrm{P}$ cells. MEX-5 disappears from the $\mathrm{AB}$ cells, but is still present in the anterior daughters of each $\mathrm{P}$ division. (D) In the eight-cell embryo, $\mathrm{P}$ granules and PIE-1 are now restricted to the $\mathrm{P}_{3}$ cell. $\mathrm{P}_{3}$ will undergo asymmetric division to produce the $\mathrm{D}$ cell and $\mathrm{P}_{4}$ to which $\mathrm{P}$ granules and PIE-1 are segregated. Nuclear PAL-1 is present in all posterior nuclei; however, it influences the fate of the C and D cells only, as its effects are repressed by PIE-1 in the P lineage and SKN-1 protein (not shown) in EMS and its descendents.

Spatially-confined laser ablation studies suggest that the forces driving centrosome and spindle positioning are cortically-based. Ablations of the central spindle or fragmentation of a centrosome result in movements of the liberated spindle pole or of centrosome fragments toward the cortex, revealing the extent and direction of net astral forces acting on each spindle pole or centrosome (Grill et al., 2001; Grill et al., 2003; Labbé et al., 2004). During rotation, forces acting on the anterior centrosome are stronger and thus pull the centrosomes and associated pronuclei towards the anterior (Figure 2C; Labbé et al., 2004). After rotation is complete, forces acting on the 
posterior centrosome strengthen, but the anterior centrosome is tethered to the anterior cortex and thus a central position of the spindle is maintained (Labbé et al., 2004). During metaphase and anaphase, the tether is released (Labbé et al., 2004) and posterior forces increase, causing the rapid posterior movement and oscillations of the posterior spindle pole (Figure 2D; Grill et al., 2001).

\subsection{A G protein pathway transduces polarity cues to a force generation machinery}

A heterotrimeric $\mathrm{G}$ protein signaling pathway acts downstream of the PAR proteins to transduce polarity cues into appropriate force generation. Two redundant G $\alpha$ subunits, GOA-1 and GPA-16, are required for rotation and asymmetric spindle movements (Gotta and Ahringer, 2001; Tsou et al., 2003). Spindle severing and centrosome fragmentation experiments show that these proteins are required for the majority of force generation during anaphase (Colombo et al., 2003; Grill et al., 2003). The GoLoco-motif proteins GPR-1/GPR-2 are similarly required for force generation (Colombo et al., 2003 ; Grill et al., 2003) and are related to PINS, which functions during asymmetric cell division in Drosophila (Schaefer et al., 2000; Yu et al., 2000). The phenotype of gpr-1/gpr-2(RNAi) is identical to that of simultaneously inactivating goa-1 and gpa-16, and GPR-1/GPR-2 act as guanine nucleotide dissociation inhibitors towards GOA-1 (Afshar et al., 2004; Gotta et al., 2003). Thus, it has been suggested that G $\alpha$-GDP might be the active signaling species for force generation (Colombo et al., 2003). Although loss of G $\beta \gamma$ also produces spindle positioning defects in one-cell embryos (Gotta and Ahringer, 2001; Zwaal et al., 1996), they are suppressed by loss of $G \alpha$ activity (Gotta and Ahringer, 2001; Tsou et al., 2003). This suggests that G $\beta \gamma$ does not play a positive role in spindle positioning in one-cell stage embryos, but rather acts as a negative regulator of $\mathrm{G} \alpha$, probably by sequestering it in the inactive heterotrimer.

How does G protein activity lead to asymmetric force generation on spindle poles? GOA-1 and GPA-16 are uniformly distributed at the cortex and around the asters (Afshar et al., 2004; Gotta and Ahringer, 2001; Miller and Rand, 2000; M.F. Tsou and L. Rose, as well as K. Colombo, K. Afshar and P. Gönczy, unpublished observations), as is LIN-5, a coiled-coil protein required for asymmetric spindle positioning and for cortical GPR-1/GPR-2 distribution (Srinivasan et al., 2003). In contrast, GPR-1/GPR-2 are enriched at the posterior of the embryo from metaphase through cytokinesis in a PAR-dependent manner, and could thus provide asymmetry of G $\alpha$ signaling during that time (Colombo et al., 2003; Gotta et al., 2003; Tsou et al., 2003).

In addition to AP polarity cues, GPR-1/GPR-2 asymmetry requires let-99 function (Tsou et al., 2003). LET-99 is a DEP domain protein needed for proper nuclear rotation and anaphase spindle movements and it is asymmetrically localized in a posterior cortical band in response to PAR proteins (Tsou et al., 2002; Tsou et al., 2003; Figure 2C). In let-99 mutant embryos, GPR-1/GPR-2 localization is uniform during anaphase, and appears stronger at the cortex in early stages. Thus, LET-99 appears to inhibit GPR-1/GPR-2 localization to the cortex. In addition, comparison of single and double mutant phenotypes supports the hypothesis that LET-99 antagonizes G $\alpha /$ GPR-1/GPR-2 activity (Tsou et al., 2003). These findings have led to the model that during prophase, when the LET-99 band appears but GPR-1/GPR-2 localization is still uniform, force generation is inhibited in the lateral posterior cortex. This would result in stronger forces pulling from both the entire anterior cortex and a small region of the posterior cortex, thus inducing rotation (Figure 2C). Because the LET-99 band is posteriorly positioned, this model is consistent with the laser ablation studies showing that the net anterior forces are higher than posterior forces during prophase. During anaphase, higher levels of GPR-1/GPR-2 at the posterior could produce higher G $\alpha$ activity and thus greater pulling force towards the posterior (Figure 2D). Exactly how LET-99 modulates G protein activity at the molecular level is an interesting question for future studies.

The cell autonomous nature of spindle positioning in the P lineage is consistent with the idea that $\mathrm{G} \alpha$ and GPR-1/GPR-2 function as part of a receptor-independent G protein pathway (reviewed in Hampoelz and Knoblich, 2004; see Heterotrimeric G-proteins in C. elegans). However, details of the activation mechanism remain to be determined. In particular, how the heterotrimer gets dissociated in the absence of an activated receptor, and the nucleotide state of the $\mathrm{G} \alpha$ species that activates downstream effectors, are not known. Evidence that a nucleotide cycle is critical for $\mathrm{G} \alpha$ signaling comes from the analysis of RIC-8 and RGS-7, which are both required for normal anaphase spindle positioning (Afshar et al., 2004; Couwembergs et al., 2004; Hess et al., 2004; Miller and Rand, 2000). RIC-8 has guanine nucleotide exchange activity (GEF) on GOA-1 (Afshar et al., 2004; Hess et al., 2004), while RGS-7 can activate GOA-1's GTPase activity (Hess et al., 2004). Severing experiments show that like G $\alpha$, RIC-8 is required for force generation on both spindle poles (Afshar et al., 2004). Thus, G $\alpha$-GTP might appear to be the active signaling species for force generation. However, RIC-8 is required for binding of GPR-1/GPR-2 to GOA-1, but not the reverse (Afshar et al., 2004), and ric-8 is also needed for efficient cortical GPR-1/GPR-2 localization (Afshar et al., 2004; Couwembergs et al., 2004). Thus, RIC-8 appears to act upstream of GPR-1/GPR-2.

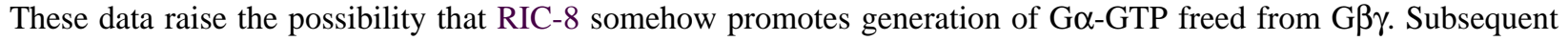


hydrolysis to G $\alpha$-GDP, followed by binding to GPR-1/GPR-2 could then form the active species (Afshar et al., 2004). Loss of RGS-7 results in low forces on the anterior spindle pole only (Hess et al., 2004), lending further support to the possibility that G $\alpha-G D P$ is the active species, at the least on the anterior side.

\subsection{Potential downstream targets of the pathway}

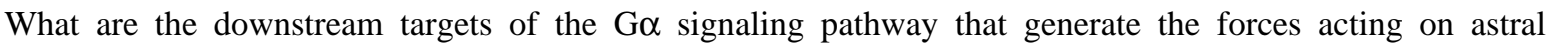
microtubules during spindle positioning? Given the complexity of $G$ protein pathways and microtubule dynamics, multiple downstream targets are anticipated. Centration and rotation depend on long astral microtubules and the molecular motor dynein and its associated subunits (Cockell et al., 2004; Gönczy et al., 1999; Matthews et al., 1998; Schmidt et al., 2005; Skop and White, 1998; Yoder and Han, 2001). Dynein is localized on the spindle, in the cytoplasm and weakly at the cortex (Gönczy et al., 1999). Because dynein is a minus end directed microtubule motor, it is thought that cortically-anchored dynein pulls on astral microtubules to generate forces for centration and rotation. A weak reduction in dynein also prevents formation of the disk shape aster (Severson and Bowerman, 2003), raising the possibility that dynein plays a role during anaphase. However, inactivation of the dynein heavy chain, $d h c-1$, using temperature-sensitive mutant alleles does not prevent anaphase spindle positioning, even though other dynein-dependent processes, including centration/rotation can be affected using these alleles (Schmidt et al., 2005). Thus, it would appear that dynein is not a major contributor to force generation during anaphase. Alternatively, because these temperature-sensitive alleles are not null, and because more microtubules contact the cell cortex during anaphase than during centration/rotation, perhaps there is sufficient residual dynein activity under these conditions to mediate anaphase movements. Overall, dynein and its associated subunits remain plausible candidates for regulation by $\mathrm{G}$ protein signaling, as are other microtubule associated proteins. Furthermore, microtubules could be a direct target of this regulation, a possibility suggested by the observation that bovine brain $\mathrm{G} \alpha$ modulates microtubule dynamics in vitro (Roychowdhury et al., 1999). Studies of cortical microtubule-residency time in one-cell stage $C$. elegans embryos have revealed that the anterior has less dynamic microtubules than the posterior during metaphase and anaphase, and this difference is PAR-dependent (Labbé et al., 2003). However, residency time is much less affected by loss of $\mathrm{G} \alpha$ signaling than would be anticipated from the laser ablation experiments (Labbé et al., 2003), and thus how residency time relates to force generation remains to be clarified.

\section{The two-cell stage embryo: formation of the dorsal/ventral axis}

The daughters of the first asymmetric division display different developmental fates and division patterns. The $\mathrm{AB}$ cell undergoes a symmetric division in which the spindle is oriented on an axis perpendicular to the AP axis (Figure 5B). This orientation is controlled by the PAR proteins, as PAR-3 prevents placement of the spindle onto the AP axis (Cheng et al., 1995; Tsou et al., 2003). In contrast, as in the one-cell stage ( $\left.\mathrm{P}_{0}\right), \mathrm{P}_{1}$ undergoes an asymmetric division with its spindle oriented on the AP axis, following a $90^{\circ}$ rotation of the centrosomes and associated nucleus prior to mitosis (Figure 5B; Hyman and White, 1987). Asymmetric division of $\mathrm{P}_{1}$ depends on the PAR proteins. Although PAR-2/PAR-1 are initially present around the entire cortex in $\mathrm{P}_{1}$ (Figure 5A), an anterior PAR-3 domain forms during prophase, and PAR-2 and PAR-1 recede to the posterior cortex, as do P granules (Figure 5B; Boyd et al., 1996; Etemad-Moghadam et al., 1995; Guo and Kemphues, 1995; Hird et al., 1996). This suggests that polarity is actively reestablished in $\mathrm{P}$, a view substantiated by mutants such as ooc-5 and ooc-3 in which PAR localization is largely normal in the one-cell, but not in $\mathrm{P}$ (Basham and Rose, 1999; Pichler et al., 2000). GFP-PAR-6 localization in $\mathrm{P}_{1}$ is coincident with a flow of cortical GFP-NMY-2 similar to that seen in $\mathrm{P}_{0}$ (Munro et al., 2004), but the cue for this flow has not been identified. Thus, the events that polarize $\mathrm{P}_{1}$ are similar, but not identical, to those in $\mathrm{P}_{0}$.

The movements that determine spindle position in $\mathrm{P}_{1}$ are also similar to those described for $\mathrm{P}$ (Figure 5B). Moreover, G $\alpha$, GPR-1/GPR-2, LET-99 and dynein are all required for nuclear rotation in $\mathrm{P}_{1}$ (Colombo et al., 2003; Gotta and Ahringer, 2001; Gotta et al., 2003; Rose and Kemphues, 1998a; Schmidt et al., 2005; Srinivasan et al., 2003) and LET-99 is localized in a band pattern (Tsou et al., 2002), presumably in response to PAR cues. Embryos with impaired $\mathrm{G} \beta \gamma$ function have abnormal centrosome positioning and late rotation in $\mathrm{P}_{1}$ (Gotta and Ahringer, 2001) but it remains to be determined if these defects are due to excess $G \alpha$ signaling, as for $P_{0}$, or whether $G \beta \gamma$ plays a direct role in $\mathrm{P}_{1}$ spindle positioning. Anaphase spindle positioning has not been analyzed extensively in $\mathrm{P}$, but may follow the same rules as in P given that GPR-1/GPR-2 are enriched at the posterior cortex here as well (Colombo et al., 2003; Gotta et al., 2003; Tsou et al., 2003).

There are several other genes required for $\mathrm{P}$ nuclear rotation, but their precise roles remain to be determined. For example, spn-4 was originally described based on centrosome positioning defects at the two-cell stage (Gomes et al., 2001). However, SPN-4 is now known to be involved in translation regulation (Huang et al., 2002; Ogura et 
al., 2003) and thus defective spindle orientation may be due to defects in translation of some of the aforementioned factors. An interesting aspect of the spn-4 phenotype is that PAR domains in $\mathrm{P}_{1}$ are initially normal, but then realign with the transverse spindle later in the cell cycle; this suggests the existence of a mechanism that reinforces alignment of the spindle with cell polarity (Gomes et al., 2001).

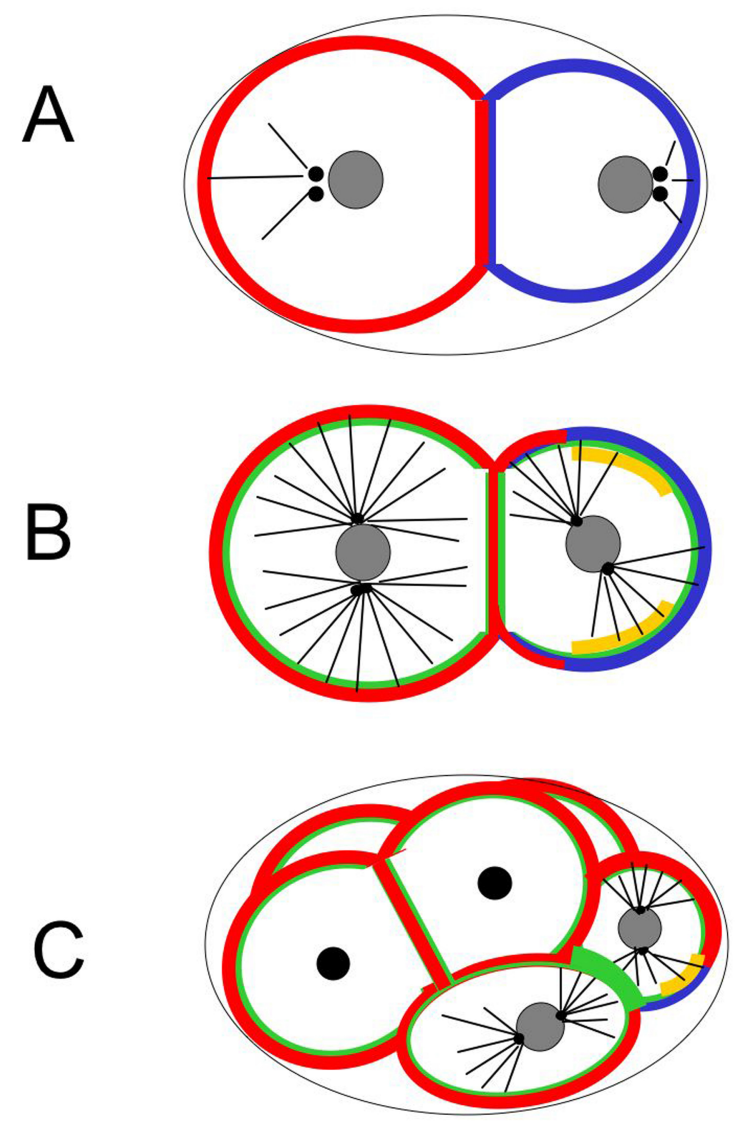

Figure 5. Polarity and spindle positioning in two to six-cell stage embryos. Centrosomes: black discs; microtubules: black lines; nuclei: gray circles; cortical PAR-3/PAR-6/PKC-3: red; cortical PAR-2 and PAR-1: blue; cortical GPR-1/2: green; cortical LET-99: gold. (A) Early two-cell stage. As a result of asymmetric spindle elongation during anaphase, the first division was unequal and generated a larger anterior blastomere $\mathrm{AB}$ and a smaller posterior blastomere $\mathrm{P}_{1}$. PAR-2 and PAR-1 are initially present around the entire cortex of $\mathrm{P}_{1}$. GPR-1/2 and LET-99 are not shown: in the early two-cell embryo, they are initially enriched in patterns similar to that seen at the end of first division. (B) After the centrosomes migrate on to a transverse plane, the P nucleus rotates $90^{\circ}$ during late prophase to align the centrosomes on the AP axis. By this time, asymmetric PAR domains have been reestablished, and a band of cortical LET-99 becomes detectable; cortical GPR-1/2 are uniform at this stage. For simplicity, LET-99 is shown as a band, but lower levels are present throughout the remaining cortex of both $\mathrm{P}_{1}$ and AB. During mitosis (not shown), higher levels of GPR-1/2 are present at the posterior cortex in $\mathrm{P}_{1}$, and asymmetric spindle elongation occurs. (C) At third cleavage the AB cells divide along the left/right plane; the spindles shift slightly anteriorly during telophase, such that the left daughters assume a more anterior position. The EMS nucleus rotates $90^{\circ}$ to align on the AP axis, while the $\mathrm{P}$, nucleus rotates $45^{\circ}$; both movements are directed towards the cell contact region between EMS and $\mathrm{P}_{2}$, where GPR-1/2 levels are highest. Cortical LET-9 9 is present as a lateral band in $\mathrm{P}_{2}$ and is absent from the EMS- $\mathrm{P}_{2}$ cell contact.

After asymmetric division of the two-cell embryo, localized cell fate determinants lead to unique fates for $\mathrm{P}$ and EMS, with EMS defining the ventral portion of the embryo (Figure 4C). Further, the second division spindle positions, combined with the constraints of the eggshell, lead to a stereotypical arrangement of cell contacts in the four-cell embryo Figure 5C) that play a critical role in cell signaling that distinguishes dorsal from ventral. Only the AB daughters express the GLP-1 receptor (Evans et al., 1994), while P expresses the APX-1 ligand (Figure 4C; Mickey et al., 1996; see Translational control of maternal RNAs). Thus GLP-1 signaling is asymmetrically activated in ABp through contact with $\mathrm{P}_{\text {, }}$, which induces dorsal fates in ABp's descendents (Mango et al., 1994; Mello et al., 1994; Moskowitz et al., 1994; see Notch signaling in the C. elegans embryo and LIN-12/Notch signaling in $C$. elegans). At the same time, $\mathrm{P}_{2}$ signals to EMS via both a Wnt signaling pathway (Rocheleau et al., 1997; Thorpe et al., 1997; see Wnt signaling) and a SRC-1/MES-1 signaling pathway (Bei et al., 2002) which polarize EMS and permit its later asymmetric division (Figure 4C, D). 


\section{The four-cell stage embryo: formation of the left/right axis}

At third cleavage, the left/right (LR) axis is determined by the divisions of $A B a$ and $A B p$, whereas asymmetric divisions of $\mathrm{P}$ and EMS further refine cell fates. Although the spindles of $\mathrm{ABa}$ and $\mathrm{ABp}$ set up orthogonal with respect to the AP and DV axes, the spindles skew towards the anterior during telophase. The lefthand daughters are thus more anterior in position and have different cell-cell contacts than their righthand counterparts (Figure 4C; Sulston et al., 1983; Wood, 1991). Subsequent signaling between the AB and MS descendents, again utilizing GLP-1, produces distinct lineages on the left and right sides (Hutter and Schnabel, 1995). This leads to the invariant left/right handedness of the adult (Bergmann et al., 1998). The only component known to play a major role in left/right handedness is the G $\alpha$ GPA-16 (Bergmann et al., 2003). Temperature sensitive gpa-16 mutants raised at intermediate temperature have variable $\mathrm{ABa}$ and $\mathrm{ABp}$ spindle positions. In some cases, the telophase shift in $\mathrm{ABa}$ and $\mathrm{ABp}$ is reversed, which correlates with the production of adult worms with reversed handedness. It remains to be determined if $G$ protein signaling is part of the cue for left/right handedness, or whether the G protein pathway is responding to an asymmetry established earlier during development.

After the $\mathrm{ABa}$ and $\mathrm{ABp}$ cells divide, EMS divides asymmetrically to produce E, the precursor of all intestinal tissue, and MS, a major muscle precursor (Sulston et al., 1983). The Wnt and SRC-1/MES-1 signaling pathways function to polarize EMS such that the daughter born next to $\mathrm{P}$ attains $\mathrm{E}$ fate (Figure 4C, D; Bei et al., 2002; Goldstein, 1992; Rocheleau et al., 1997; Thorpe et al., 1997); both signaling pathways also function in orientation of the EMS spindle towards P (Figure 5C; Goldstein, 1992; Schlesinger et al., 1999). Many components of the canonical Wnt signaling pathway play a role in E cell specification. Only some of them are also used for EMS spindle positioning. Interestingly however, several of these are shared with the "non-canonical" Wnt signaling pathway that establishes planar cell polarity in Drosophila (Rocheleau et al., 1997; Schlesinger et al., 1999; Thorpe et al., 1997; Walston et al., 2004). The downstream targets in C. elegans that function specifically in EMS spindle positioning remain to be identified. The SRC-1/MES-1 pathway for EMS spindle positioning acts at least in part through G $\alpha$ signaling and LET-99. GPR-1/GPR-2 are enriched at the EMS/P cell contact region (Figure 5C), along with their cortical partner LIN-5 (Gotta et al., 2003; Srinivasan et al., 2003; Tsou et al., 2003). This localization depends on MES-1 but not Wnt signaling. Further, temperature sensitive gpa-16 mutant embryos showed a partially penetrant defect in EMS spindle orientation when shifted to the restrictive temperature after a normal second division (Tsou et al., 2003). In contrast to GPR-1/GPR-2, LET-99 is absent from the EMS/P cell contact, but is uniformly localized to the remaining cortex. This pattern is also dependent on MES-1 signaling, and temperature shifts of let-99ts embryos during second division result in uniform GPR-1/GPR-2 and failure of rotation in EMS at the four-cell stage (Tsou et al., 2003). Thus, a similar G protein module may be used for spindle alignment in EMS, but the role of other $\mathrm{G}$ protein signaling components, as well as the downstream targets that execute this alignment, remain to be elucidated.

After EMS division is complete, $\mathrm{P}$ undergoes asymmetric division to produce $\mathrm{C}$, a muscle and hypodermis precursor and $\mathrm{P}_{3}$, which divides asymmetrically to produce $\mathrm{D}$, a muscle precursor and $\mathrm{P}$, the germ-line precursor (Figure 1D; Figure 4D; Sulston et al., 1983; reviewed in Schnabel and Priess, 1997). PAR domains are established in $\mathrm{P}_{2}$ and $\mathrm{P}_{3}$, but their position, as well as the orientation of the asymmetric divisions, are reversed with respect to the earlier divisions (Figure 5C; Schierenberg, 1987). Reversal of polarity is also dependent on MES-1 function (Berkowitz and Strome, 2000; reviewed in Kemphues and Strome, 1997)

As a result of the asymmetric divisions and cell interactions described above, numerous cell fate determinants become differentially localized to specific cells or subsets of cells in the early embryo (Figure 4). These determinants then interact to instruct each of the founder cells to carry out a specific pattern of cell division and developmental program which will ultimately result in the making of an embryo ready to hatch.

\section{Evolutionarily conserved themes}

Many of the findings made in the early C. elegans embryo and that were briefly reviewed above have had important bearing on understanding related biological processes in other organisms. Thus, the PAR proteins play a central role in cell polarity across metazoan evolution (reviewed in Kemphues, 2000). For instance, Drosophila Bazooka encodes a PAR-3 homologue that forms a complex with DmPar6 and an atypical protein kinase C; this complex is located on the apical side of epithelial cells and neuroblasts and is required for their proper polarity (reviewed in Doe, 2001). A complex containing Par3/Par6/aPKC is also present in apically located tight junctions of polarized mammalian epithelial cells (Izumi et al., 1998). Moreover, overexpression of a dominant negative mutant of aPKC results in defective surface polarity of mammalian MDCK epithelial cells (Suzuki et al., 2001). Similarly, 
Drosophila DmPar-1 is required notably for maintaining polarity in the follicular epithelium during oogenesis (Shulman et al., 2000; Tomancak et al., 2000), whereas its mammalian counterpart promotes formation of tight junctions in MDCK cells (Bohm et al., 1997; Cohen et al., 2004). Taken together, these observations indicate that the function of the PAR proteins has been significantly conserved across metazoan evolution.

The use of PAR proteins to regulate G protein signaling also appears to be conserved (reviewed in Hampoelz and Knoblich, 2004). In Drosophila neuroblasts and sensory organ precursors, Bazooka directs asymmetric distribution of $\mathrm{G}_{i}$ and PINS (a GPR-1/GPR-2 homologue) to one side of the cell, and both G $\alpha_{i}$ and PINS are required for proper spindle positioning. Despite the common use of the PAR and G proteins in asymmetric division in C. elegans and Drosophila, there are clear differences as well between the two systems. For instance, whereas $\mathrm{G} \beta \gamma$ function in C. elegans merely serves to dampen $\mathrm{G} \alpha$ activity, as discussed above, it appears to be essential for generating spindle asymmetry in Drosophila neuroblasts (Fuse et al., 2003; Yu et al., 2003). In addition, there is no clear orthologue of LET-99 in Drosophila, although potential orthologues are found in the mouse and human genomes (L.Rose, unpublished). Interestingly, the requirement for $\mathrm{G} \alpha$ proteins in ensuring spindle positioning extends to mammals. Indeed, LGN, a mammalian homologue of GPR-1/GPR-2 and PINS, is recruited to the cortex through association with $\mathrm{G} \alpha$ (Du and Macara, 2004). LGN also associates with the microtubule-binding protein NuMA, which may thus be brought to the cell cortex to act as an effector of spindle positioning (Du and Macara, 2004). Whereas the effectors that govern spindle positioning remain to be identified in both C. elegans and Drosophila, these findings illustrate that work in multiple systems will lead to a greater understanding of the regulation of spindle positioning by cellular polarity across metazoan evolution.

As discussed above, the mechanisms of cellular polarity and asymmetric division that determine the AP axis in C. elegans have clear parallels in other organisms. Likewise, the specification of the other axes of the C. elegans embryo, as well as that of particular cell fates, utilize highly conserved signaling modules, including the Wnt and Notch signaling pathways (see Wnt signaling, Notch signaling in the C. elegans embryo and LIN-12/Notch signaling in $C$. elegans). Thus, just as the study of the early $C$. elegans embryo provided key insight into developmental processes, studies in other systems inform the work in C. elegans to give a broader picture of the mechanisms that control development.

\section{Acknowledgements}

We are grateful to Katayoun Afshar, Kenneth Kemphues, Eric Mortensen and Daniel Starr for critical reading of the manuscript. We thank Ed Munro for providing us with Movie 3. Research in the Gönczy laboratory is supported by the Swiss National Science Foundation (3100A0-102087) and Oncosuisse (OCS-01495-02-2004), that in the Rose laboratory by the NIH (R01GM068744-01A1) and previously by the American Cancer Society (RPG-00-076-1-ddc).

\section{References}

Afshar, K., Willard, F.S., Colombo, K., Johnston, C.A., McCudden, C.R., Siderovski, D.P., and Gönczy, P. (2004). RIC-8 is required for GPR-1/2-dependent Galpha function during asymmetric division of C. elegans embryos. Cell 119, 219-230. Abstract Article

Albertson, D.G. (1984). Formation of the first cleavage spindle in nematode embryos. Dev. Biol. 101, 61-72. Abstract Article

Basham, S.E., and Rose, L.S. (1999). Mutations in ooc-5 and ooc-3 disrupt oocyte formation and the reestablishment of asymmetric PAR protein localization in two-cell Caenorhabditis elegans embryos. Dev. Biol. 215, 253-263. Abstract Article

Bei, Y., Hogan, J., Berkowitz, L.A., Soto, M., Rocheleau, C.E., Pang, K.M., Collins, J., and Mello, C.C. (2002). SRC-1 and Wnt signaling act together to specify endoderm and to control cleavage orientation in early $C$. elegans embryos. Dev. Cell 3, 113-125. Abstract Article

Bergmann, D.C., Crew, J.R., Kramer, J.M., and Wood, W.B. (1998). Cuticle chirality and body handedness in Caenorhabditis elegans. Dev. Genet. 23, 164-174. Abstract 
Bergmann, D.C., Lee, M., Robertson, B., Tsou, M.F., Rose, L.S., and Wood, W.B. (2003). Embryonic handedness choice in C. elegans involves the Galpha protein GPA-16. Development 130,5731-5740. Abstract Article

Berkowitz, L.A., and Strome, S. (2000). MES-1, a protein required for unequal divisions of the germline in early $C$. elegans embryos, resembles receptor tyrosine kinases and is localized to the boundary between the germline and gut cells. Development 127, 4419-4431. Abstract

Bohm, H., Brinkmann, V., Drab, M., Henske, A., and Kurzchalia, T.V. (1997). Mammalian homologues of $C$. elegans PAR-1 are asymmetrically localized in epithelial cells and may influence their polarity. Curr. Biol. 7, 603-606. Abstract Article

Boyd, L., Guo, S., Levitan, D., Stinchcomb, D.T., and Kemphues, K.J. (1996). PAR-2 is asymmetrically distributed and promotes association of $\mathrm{P}$ granules and PAR-1 with the cortex in C. elegans embryos. Development 122 , 3075-3084. Abstract

Cheeks, R.J., Canman, J.C., Gabriel, W.N., Meyer, N., Strome, S., and Goldstein, B. (2004). C. elegans PAR proteins function by mobilizing and stabilizing asymmetrically localized protein complexes. Curr. Biol. 14, 851-862. Abstract Article

Cheng, N.N., Kirby, C.M., and Kemphues, K.J. (1995). Control of cleavage spindle orientation in Caenorhabditis elegans: the role of the genes par-2 and par-3. Genetics 139, 549-559. Abstract

Cockell, M.M., Baumer, K., and Gönczy, P. (2004). lis-1 is required for dynein-dependent cell division processes in C. elegans embryos. J. Cell Sci. 117, 4571-4582. Abstract Article

Cohen, D., Brennwald, P.J., Rodriguez-Boulan, E., and Musch, A. (2004). Mammalian PAR-1 determines epithelial lumen polarity by organizing the microtubule cytoskeleton. J. Cell Biol. 164, 717-727. Abstract Article

Colombo, K., Grill, S.W., Kimple, R.J., Willard, F.S., Siderovski, D.P., and Gönczy, P. (2003). Translation of polarity cues into asymmetric spindle positioning in Caenorhabditis elegans embryos. Science 300, $1957-1961$. Abstract Article

Couwenbergs, C., Spilker, A.C., and Gotta, M. (2004). Control of embryonic spindle positioning and G $\alpha$ activity by RIC-8. Curr. Biol. 14, 1871-1876. Abstract Article

Cowan, C.R., and Hyman, A.A. (2004). Centrosomes direct cell polarity independently of microtubule assembly in C. elegans embryos. Nature 431, 92-96. Abstract Article

Cuenca, A.A., Schetter, A., Aceto, D., Kemphues, K., and Seydoux, G. (2003). Polarization of the C. elegans zygote proceeds via distinct establishment and maintenance phases. Development 130, 1255-1265. Abstract Article

DeRenzo, C., Reese, K.J., and Seydoux, G. (2003). Exclusion of germ plasm proteins from somatic lineages by cullin-dependent degradation. Nature 424, 685-689. Abstract Article

Doe, C.Q. (2001). Cell polarity: the PARty expands. Nat. Cell Biol. 3, E7-E9. Abstract Article

Draper, B.W., Mello, C.C., Bowerman, B., Hardin, J., and Priess, J.R. (1996). MEX-3 is a KH domain protein that regulates blastomere identity in early C. elegans embryos. Cell 87, 205-216. Abstract Article

Du, Q., and Macara, I.G. (2004). Mammalian Pins is a conformational switch that links NuMA to heterotrimeric G proteins. Cell 119, 503-516. Abstract Article

Etemad-Moghadam, B., Guo, S., and Kemphues, K.J. (1995). Asymmetrically distributed PAR-3 protein contributes to cell polarity and spindle alignement in early C. elegans embryos. Cell 83, 743-752. Abstract Article

Evans, T.C., Crittenden, S.L., Kodoyianni, V., and Kimble, J. (1994). Translational control of maternal $g l p-1$ mRNA establishes an asymmetry in the C. elegans embryo. Cell 77, 183-194. Abstract Article 
Fuse, N., Hisata, K., Katzen, A.L., and Matsuzaki, F. (2003). Heterotrimeric G proteins regulate daughter cell size asymmetry in Drosophila neuroblast divisions. Curr. Biol. 13, 947-954. Abstract Article

Goldstein, B. (1992). Induction of gut in Caenorhabditis elegans embryos. Nature 357, 255-257. Abstract Article

Goldstein, B., and Hird, S.N. (1996). Specification of the anteroposterior axis in Caenorhabditis elegans. Development 122, 1467-1474. Abstract

Gomes, J.E., Encalada, S.E., Swan, K.A., Shelton, C.A., Carter, J.C., and Bowerman, B. (2001). The maternal gene spn-4 encodes a predicted RRM protein required for mitotic spindle orientation and cell fate patterning in early $C$. elegans embryos. Development 128, 4301-4314. Abstract

Gönczy, P., Pichler, S., Kirkham, M., and Hyman, A.A. (1999). Cytoplasmic dynein is required for distinct aspects of MTOC positioning, including centrosome separation, in the one cell stage Caenorhabditis elegans embryo. J. Cell Biol. 147, 135-150. Abstract Article

Gotta, M., Abraham, M.C., and Ahringer, J. (2001). CDC-42 controls early cell polarity and spindle orientation in $C$. elegans. Curr. Biol. 11, 482-488. Abstract Article

Gotta, M., and Ahringer, J. (2001). Distinct roles for Galpha and Gbetagamma in regulating spindle position and orientation in Caenorhabditis elegans embryos. Nat. Cell Biol. 3, 297-300. Abstract Article

Gotta, M., Dong, Y., Peterson, Y.K., Lanier, S.M., and Ahringer, J. (2003). Asymmetrically distributed C. elegans homologs of AGS3/PINS control spindle position in the early embryo. Curr. Biol. 13, 1029-1037. Abstract Article

Grill, S.W., Gönczy, P., Stelzer, E.H., and Hyman, A.A. (2001). Polarity controls forces governing asymmetric spindle positioning in the Caenorhabditis elegans embryo. Nature 409, 630-633. Abstract Article

Grill, S.W., Howard, J., Schaffer, E., Stelzer, E.H., and Hyman, A.A. (2003). The distribution of active force generators controls mitotic spindle position. Science 301, 518-521. Abstract Article

Guedes, S., and Priess, J.R. (1997). The C. elegans MEX-1 protein is present in germline blastomeres and is a P granule component. Development 124, 731-739. Abstract

Guo, S., and Kemphues, K.J. (1995). par-1, a gene required for establishing polarity in C. elegans embryos, encodes a putative Ser/Thr kinase that is asymmetrically distributed. Cell 81, 611-620. Abstract Article

Hamill, D.R., Severson, A.F., Carter, J.C., and Bowerman, B. (2002). Centrosome maturation and mitotic spindle assembly in $C$. elegans require SPD-5, a protein with multiple coiled-coil domains. Dev. Cell 3, 673-684. Abstract Article

Hampoelz, B., and Knoblich, J.A. (2004). Heterotrimeric G proteins: new tricks for an old dog. Cell 119, $453-456$. Abstract Article

Hess, H.A., Röper, J.-C., Grill, S.W., and Koelle, M.R. (2004). RGS-7 completes a receptor-independent heterotrimeric $\mathrm{G}$ protein cycle to asymmetrically regulate mitotic spindle positioning in C. elegans. Cell 119, 209-218. Abstract Article

Hird, S.N., Paulsen, J.E., and Strome, S. (1996). Segregation of germ granules in living Caenorhabditis elegans embryos: type-specific mechanisms for cytoplasmic localization. Development 122, 1303-1312. Abstract

Hird, S.N., and White, J.G. (1993). Cortical and cytoplasmic flow polarity in early embryonic cells of Caenorhabditis elegans. J. Cell Biol. 1343-1355. Abstract

Huang, N.N., Mootz, D.E., Walhout, A.J., Vidal, M., and Hunter, C.P. (2002). MEX-3 interacting proteins link cell polarity to asymmetric gene expression in Caenorhabditis elegans. Development 129, 747-759. Abstract

Hung, T.J., and Kemphues, K.J. (1999). PAR-6 is a conserved PDZ domain-containing protein that colocalizes with PAR-3 in Caenorhabditis elegans embryos. Development 126, 127-135. Abstract 
Hunter, C.P., and Kenyon, C. (1996). Spatial and temporal controls target pal-1 blastomere-specification activity to a single blastomere lineage in C. elegans embryos. Cell 87, 217-226. Abstract Article

Hutter, H., and Schnabel, R. (1995). Establishment of left-right asymmetry in the Caenorhabditis elegans embryo: a multistep process involving a series of inductive events. Development 121, 3417-3424. Abstract

Hyman, A.A., and White, J.G. (1987). Determination of cell division axes in the early embryogenesis of Caenorhabditis elegans. J. Cell Biol. 105, 2123-2135. Abstract Article

Izumi, Y., Hirose, T., Tamai, Y., Hirai, S., Nagashima, Y., Fujimoto, T., Tabuse, Y., Kemphues, K.J., and Ohno, S. (1998). An atypical PKC directly associates and colocalizes at the epithelial tight junction with ASIP, a mammalian homologue of Caenorhabditis elegans polarity protein PAR-3. J. Cell Biol. 143, 95-106. Abstract Article

Kay, A.J., and Hunter, C.P. (2001). CDC-42 regulates PAR protein localization and function to control cellular and embryonic polarity in C. elegans. Curr. Biol. 11, 474-481. Abstract Article

Kemphues, K. (2000). PARsing embryonic polarity. Cell 101, 345-348. Abstract Article

Kemphues, K.J., Priess, J.R., Morton, D.G., and Cheng, N. (1988). Identification of genes required for cytoplasmic localization in early $C$. elegans embryos. Cell 52, 311-320. Abstract Article

Kemphues, K.J., and Strome, S. (1997). Fertilization and establishment of polarity in the embryo. In C. elegans II, D.L. Riddle, T. Blumenthal, B.J. Meyer, and J.R. Priess, eds. (Cold Spring Harbor Laboratory Press), pp. $335-359$.

Labbé, J.C., Maddox, P.S., Salmon, E.D., and Goldstein, B. (2003). PAR proteins regulate microtubule dynamics at the cell cortex in C. elegans. Curr. Biol. 13, 707-714. Abstract Article

Labbé, J.C., McCarthy, E.K., and Goldstein, B. (2004). The forces that position a mitotic spindle asymmetrically are tethered until after the time of spindle assembly. J. Cell. Biol. 167, 245-256. Abstract Article

Mango, S.E., Thorpe, C.J., Martin, P.R., Chamberlain, S.H., and Bowerman, B. (1994). Two maternal genes, apx-1 and pie-1, are required to distinguish the fates of equivalent blastomeres in the early Caenorhabditis elegans embryo. Development 120, 2305-2315. Abstract

Matthews, L.R., Carter, P., Thierry-Mieg, D., and Kemphues, K. (1998). ZYG-9, a Caenorhabditis elegans protein required for microtubule organization and function, is a component of meiotic and mitotic spindle poles. J. Cell Biol. 141, 1159-1168. Abstract Article

Mello, C.C., Draper, B.W., Krause, M., Weintraub, H., and Priess, J.R. (1992). The pie-1 and mex-1 genes and maternal control of blastomere identity in early C. elegans embryos. Cell 70, 163-176. Abstract Article

Mello, C.C., Draper, B.W., and Priess, J.R. (1994). The maternal genes apx-1 and glp-1 and establishment of dorsal-ventral polarity in the early $C$. elegans embryo. Cell 77, 95-106. Abstract Article

Mello, C.C., Schubert, C., Draper, B., Zhang, W., Lobel, R., and Priess, J.R. (1996). The PIE-1 protein and germline specification in C. elegans embryos. Nature 382, 710-712. Abstract Article

Mickey, K.M., Mello, C.C., Montgomery, M.K., Fire, A., and Priess, J.R. (1996). An inductive interaction in 4-cell stage C. elegans embryos involves APX-1 expression in the signalling cell. Development 122, 1791-1798. Abstract

Miller, K.G., and Rand, J.B. (2000). A role for RIC-8 (Synembryn) and GOA-1 (G alpha) in regulating a subset of centrosome movements during early embryogenesis in Caenorhabditis elegans. Genetics 156, 1649-1660. Abstract

Morton, D.G., Shakes, D.C., Nugent, S., Dichoso, D., Wang, W., Golden, A., and Kemphues, K.J. (2002). The Caenorhabditis elegans par-5 gene encodes a 14-3-3 protein required for cellular asymmetry in the early embryo. Dev. Biol. 241, 47-58. Abstract Article 
Moskowitz, I.P., Gendreau, S.B., and Rothman, J.H. (1994). Combinatorial specification of blastomere identity by glp-1-dependent cellular interactions in the nematode Caenorhabditis elegans. Development 120, 3325-3338. Abstract

Munro, E., Nance, J., and Priess, J.R. (2004). Cortical flows powered by asymmetrical contraction transport PAR proteins to establish and maintain anterior-posterior polarity in the early C. elegans embryo. Dev. Cell 7, 413-424. Abstract Article

Nigon, V., Guerrier, P., and Monin, H. (1960). L'architecture polaire de l'oeuf et les mouvements des constituants cellulaires au cours des premieres etapes du developpement chez quelques nematodes. Bull Biol. Fr. Belg. 93, 131-202.

O'Connell, K.F., Maxwell, K.N., and White, J.G. (2000). The spd-2 gene is required for polarization of the anteroposterior axis and formation of the sperm asters in the Caenorhabditis elegans zygote. Dev. Biol. 222, 55-70. Abstract Article

Oegema, K., Desai, A., Rybina, S., Kirkham, M., and Hyman, A.A. (2001). Functional analysis of kinetochore assembly in Caenorhabditis elegans. J. Cell Biol. 153, 1209-1226. Abstract Article

Ogura, K., Kishimoto, N., Mitani, S., Gengyo-Ando, K., and Kohara, Y. (2003). Translational control of maternal glp-1 mRNA by POS-1 and its interacting protein SPN-4 in Caenorhabditis elegans. Development 130, 2495-2503. Abstract Article

Pichler, S., Gönczy, P., Schnabel, H., Pozniakowski, A., Ashford, A., Schnabel, R., and Hyman, A.A. (2000). OOC-3, a novel putative transmembrane protein required for establishment of cortical domains and spindle orientation in the $\mathrm{P}(1)$ blastomere of C. elegans embryos. Development 127, 2063-2073. Abstract

Rappaport, R. (1971). Cytokinesis in animal cells. Int. Rev. Cytol. 31, 169-213. Abstract

Rappleye, C.A., Tagawa, A., Le Bot, N., Ahringer, J., and Aroian, R.V. (2003). Involvement of fatty acid pathways and cortical interaction of the pronuclear complex in Caenorhabditis elegans embryonic polarity. BMC Dev. Biol. 3, 8. Abstract Article

Rappleye, C.A., Tagawa, A., Lyczak, R., Bowerman, B., and Aroian, R.V. (2002). The anaphase-promoting complex and separin are required for embryonic anterior-posterior axis formation. Dev. Cell 2, 195-206. Abstract Article

Reese, K.J., Dunn, M.A., Waddle, J.A., and Seydoux, G. (2000). Asymmetric segregation of PIE-1 in C. elegans is mediated by two complementary mechanisms that act through separate PIE-1 protein domains. Mol. Cell 6, 445-455. Abstract Article

Rocheleau, C.E., Downs, W.D., Lin, R., Wittmann, C., Bei, Y., Cha, Y.H., Ali, M., Priess, J.R., and Mello, C.C. (1997). Wnt signaling and an APC-related gene specify endoderm in early C. elegans embryos. Cell 90, 707-716. Abstract Article

Rose, L.S., and Kemphues, K. (1998a). The let-99 gene is required for proper spindle orientation during cleavage of the C. elegans embryo. Development 125, 1337-1346. Abstract

Rose, L.S., and Kemphues, K.J. (1998b). Early patterning of the C. elegans embryo. Annu. Rev. Genet. 32, 521-545. Abstract Article

Roychowdhury, S., Panda, D., Wilson, L., and Rasenick, M.M. (1999). G protein alpha subunits activate tubulin GTPase and modulate microtubule polymerization dynamics. J. Biol. Chem. 274, 13485-13490. Abstract Article

Sadler, P.L., and Shakes, D.C. (2000). Anucleate Caenorhabditis elegans sperm can crawl, fertilize oocytes and direct anterior-posterior polarization of the 1-cell embryo. Development 127, 355-366. Abstract 
Schaefer, M., Shevchenko, A., and Knoblich, J.A. (2000). A protein complex containing Inscuteable and the Galpha-binding protein Pins orients asymmetric cell divisions in Drosophila. Curr. Biol. 10, 353-362. Abstract Article

Schierenberg, E. (1987). Reversal of cellular polarity and early cell-cell interaction in the embryos of Caenorhabditis elegans. Dev. Biol. 122, 452-463. Abstract Article

Schlesinger, A., Shelton, C.A., Maloof, J.N., Meneghini, M., and Bowerman, B. (1999). Wnt pathway components orient a mitotic spindle in the early Caenorhabditis elegans embryo without requiring gene transcription in the responding cell. Genes Dev. 13, 2028-2038. Abstract

Schmidt, D.J., Rose, D.J., Saxton, W.M., and Strome, S. (2005). Functional analysis of cytoplasmic dynein heavy chain in C. elegans with fast-acting temperature-sensitive mutations. Mol. Biol. Cell. 16(3), 1200-1212. Abstract

Schnabel, R., and Priess, J.R. (1997). Specification of cell fates in the early embryo. In C. elegans II, D.L. Riddle, T. Blumenthal, B.J. Meyer, and J.R. Priess, eds. (Cold Spring Harbor Laboratory Press), pp. 361-382.

Schubert, C.M., Lin, R., de Vries, C.J., Plasterk, R.H., and Priess, J.R. (2000). MEX-5 and MEX-6 function to establish soma/germline asymmetry in early C. elegans embryos. Mol. Cell 5, 671-682. Abstract

Severson, A.F., and Bowerman, B. (2003). Myosin and the PAR proteins polarize microfilament-dependent forces that shape and position mitotic spindles in Caenorhabditis elegans. J. Cell Biol. 161, 21-26. Abstract Article

Shulman, J.M., Benton, R., and St Johnston, D. (2000). The Drosophila homolog of C. elegans PAR-1 organizes the oocyte cytoskeleton and directs oskar mRNA localization to the posterior pole. Cell 101, 377-388. Abstract Article

Skop, A.R., and White, J.G. (1998). The dynactin complex is required for cleavage plane specification in early Caenorhabditis elegans embryos. Curr. Biol. 8, 1110-1116. Abstract Article

Sonneville, R., and Gönczy, P. (2004). zyg-11 and cul-2 regulate progression through meiosis II and polarity establishment in C. elegans. Development 131, 3527-3535, 3543. Abstract Article

Srinivasan, D.G., Fisk, R.M., Xu, H., and van den Heuvel, S. (2003). A complex of LIN-5 and GPR proteins regulates $\mathrm{G}$ protein signaling and spindle function in C elegans. Genes Dev. 17, 1225-1239.. Abstract Article

Strome, S., and Wood, W.B. (1983). Generation of asymmetry and segregation of germ-line granules in early $C$. elegans embryos. Cell 35, 15-25. Abstract Article

Sulston, J.E., Schierenberg, E., White, J.G., and Thomson, J.N. (1983). The embryonic cell lineage of the nematode Caenorhabditis elegans. Dev. Biol. 100, 64-119. Abstract Article

Suzuki, A., Yamanaka, T., Hirose, T., Manabe, N., Mizuno, K., Shimizu, M., Akimoto, K., Izumi, Y., Ohnishi, T., and Ohno, S. (2001). Atypical protein kinase C is involved in the evolutionarily conserved par protein complex and plays a critical role in establishing epithelia-specific junctional structures. J. Cell Biol. 152, 1183-1196. Abstract Article

Tabara, H., Hill, R.J., Mello, C.C., Priess, J.R., and Kohara, Y. (1999). pos-1 encodes a cytoplasmic zinc-finger protein essential for germline specification in C. elegans. Development 126,1-11. Abstract

Thorpe, C.J., Schlesinger, A., Carter, J.C., and Bowerman, B. (1997). Wnt signaling polarizes an early C. elegans blastomere to distinguish endoderm from mesoderm. Cell 90, 695-705. Abstract Article

Tomancak, P., Piano, F., Riechmann, V., Gunsalus, K.C., Kemphues, K.J., and Ephrussi, A. (2000). A Drosophila melanogaster homologue of Caenorhabditis elegans par-1 acts at an early step in embryonic-axis formation. Nat. Cell Biol. 2, 458-460. Abstract Article

Tsou, M.F., Hayashi, A., DeBella, L.R., McGrath, G., and Rose, L.S. (2002). LET-99 determines spindle position and is asymmetrically enriched in response to PAR polarity cues in C. elegans embryos. Development 129, 4469-4481. Abstract 
Tsou, M.F., Hayashi, A., and Rose, L.S. (2003). LET-99 opposes Galpha/GPR signaling to generate asymmetry for spindle positioning in response to PAR and MES-1/SRC-1 signaling. Development 130, 5717-5730. Abstract Article

Tsou, M.F., Ku, W., Hayashi, A., and Rose, L.S. (2003). PAR-dependent and geometry-dependent mechanisms of spindle positioning. J. Cell Biol. 160, 845-855. Article

Wallenfang, M.R., and Seydoux, G. (2000). Polarization of the anterior-posterior axis of C. elegans is a microtubule-directed process. Nature 408, 89-92. Abstract Article

Walston, T., Tuskey, C., Edgar, L., Hawkins, N., Ellis, G., Bowerman, B., Wood, W., and Hardin, J. (2004). Multiple Wnt signaling pathways converge to orient the mitotic spindle in early C. elegans embryos. Dev. Cell 7, 831-841. Abstract Article

Waring, D.A., and Kenyon, C. (1990). Selective silencing of cell communication influences anteroposterior pattern formation in C. elegans. Cell 60, 123-131. Abstract Article

Wood, W.B. (1991). Evidence from reversal of handedness in C. elegans embryos for early cell interactions determining cell fates. Nature 349, 536-538. Abstract Article

Yoder, J.H., and Han, M. (2001). Cytoplasmic dynein light intermediate chain is required for discrete aspects of mitosis in Caenorhabditis elegans. Mol. Biol. Cell 12, 2921-2933. Abstract

Yu, F., Cai, Y., Kaushik, R., Yang, X., and Chia, W. (2003). Distinct roles of Galphai and Gbeta13F subunits of the heterotrimeric G protein complex in the mediation of Drosophila neuroblast asymmetric divisions. J. Cell Biol. 162, 623-633. Abstract Article

Yu, F., Morin, X., Cai, Y., Yang, X., and Chia, W. (2000). Analysis of partner of inscuteable, a novel player of Drosophila asymmetric divisions, reveals two distinct steps in inscuteable apical localization. Cell 100, 399-409. Abstract Article

Zwaal, R.R., Ahringer, J., van Luenen, H.G., Rushforth, A., Anderson, P., and Plasterk, R.H. (1996). G proteins are required for spatial orientation of early cell cleavages in C. elegans embryos. Cell 86, 619-629. Abstract Article

All WormBook content, except where otherwise noted, is licensed under a Creative Commons Attribution License. 